\title{
Effect of Polydopamine Deposition Conditions on Polysulfone Ultrafiltration Membrane Properties and Threshold Flux during Oil/Water Emulsion Filtration
}

Sirirat Kasemset ${ }^{\mathrm{a}, 1}$, Zhengwang He ${ }^{\mathrm{a}}$, Daniel J. Miller ${ }^{\mathrm{a}, 2}$, Benny D. Freeman ${ }^{\mathrm{a},{ }^{*} \text {, and }}$ Mukul M. Sharma ${ }^{\text {b }}$

${ }^{a}$ University of Texas at Austin, Department of Chemical Engineering, Texas Materials Institute, and Center for Energy and Environmental Resources, 10100 Burnet Road, Building 133, Austin, TX 78758, USA

${ }^{\mathrm{b}}$ University of Texas at Austin, Department of Petroleum and Geosystems Engineering, 200 East Dean Keeton Street, Austin, TX 78712, USA

${ }^{1}$ Current address: Evonik Corporation, 4201 Evonik Road, Theodore, AL 36582, USA

${ }^{2}$ Current address: Joint Center for Artificial Photosynthesis, Lawrence Berkeley National Laboratory, 1 Cyclotron Road, Berkeley, CA, 94720, USA

* To whom correspondence should be addressed: freeman@che.utexas.edu (Tel: +1-512-232-2803, Fax: +1-512-232-2807)

Date: April 25, 2016

Manuscript prepared for submission to Polymer 


\begin{abstract}
Surface modification of porous membranes for water filtration has been extensively reported in the literature to improve fouling properties. However, surface modification can significantly change the membrane filtration properties, sometimes resulting in more severe fouling than with the original, unmodified membrane. This study focused on demonstrating surface modification strategies and membrane comparison strategies to better understand the complex, competing phenomena occurring when membranes are surface modified. Polysulfone ultrafiltration membranes were modified with polydopamine (PDA) at different initial dopamine concentrations and deposition times. Membrane properties, including surface hydrophilicity, roughness, and zeta potential, were characterized. PDA coatings significantly increased surface hydrophilicity, but they did not markedly change the surface roughness or zeta potential. The threshold flux during oil/water emulsion filtration was determined and used as a fouling parameter for membranes modified with PDA at various modification conditions. The threshold flux increased when PDA was deposited at low initial dopamine concentrations or short coating times. However, PDA deposition at high initial dopamine concentrations or long coating times decreased the threshold flux, suggesting that a tradeoff exists between increased hydrophilicity and reduced pore size due to surface modification. An increase in membrane surface hydrophilicity was observed at all PDA deposition conditions, which tends to reduce foulant adhesion and increase threshold flux. However, extensive PDA coating significantly decreased membrane pure water permeance, suggesting that some membrane pores may have been narrowed or blocked, increasing local permeate flux through the remaining pores in the PDA-modified membranes. This higher local flux would exacerbate fouling and decrease threshold flux. Comparing unmodified and PDA-modified membranes having similar pure water
\end{abstract}


permeance values, the PDA-modified membranes had higher threshold fluxes than the unmodified membranes.

\section{Keywords:}

Surface modification; ultrafiltration; threshold flux; polydopamine; membrane fouling; oil emulsion filtration 


\section{INTRODUCTION}

Fouling remains a major challenge for water purification membranes. Fouling occurs when solutes or particles in a feed solution accumulate in the membrane pores or on the membrane surface, and in turn, reduce membrane permeance $[1,2]$. Membrane surface modification can reduce fouling by altering the surface properties to weaken membrane-foulant interactions [3,4]. Surface modification studies have been reviewed elsewhere $[4,5]$. Fouling mitigation in surface-modified membranes has been linked to increases in surface hydrophilicity, decreases in surface roughness, and decreases in surface charge $[3,4,6]$. However, application of coatings or grafting materials to membrane surfaces may introduce additional mass transfer resistance to the membrane, resulting in reduced pure water permeance $[3,7,8]$. For porous membranes, the permeance decrease is often due to membrane separation layer thickness increase and pore size reduction or pore blockage caused by surface modification $[9,10]$. During constant global (i.e., overall) permeate flux filtration, pore blockage or pore size decrease could increase local convective permeate flux through the pores, enhancing the forces responsible for bringing foulants to the membrane surface, thereby increasing fouling [6].

Polydopamine (PDA) is a highly hydrophilic material which non-specifically deposits onto many substrates from alkaline, aqueous buffered solution in an aerobic environment $[8,11,12]$. PDA is stable under mild acidic and basic conditions, so it is compatible with traditional membrane cleaning chemicals [13-15]. The hydrophilic PDA surface modification can reduce hydrophobic-hydrophobic interactions between the membrane and foulants, improving membrane fouling resistance [16-20]. Nevertheless, severe reductions in membrane pure water permeance due to application of the PDA coating on porous membranes should be minimized to avoid, at fixed global or overall 
flux, increases in local permeate flux due to pore narrowing or blocking as a result of PDA modification, which could exacerbate fouling [20]. Generally, the pure water permeance of these membranes can be controlled by varying PDA modification conditions such as coating solution concentration and coating time $[8,9,17,20]$. Since even a minimal application of PDA to the membrane surface can significantly improve surface hydrophilicity, and more substantial applications of PDA have little effect on hydrophilicity, PDA can be used to examine the effect of changing pore size in a hydrophilic membrane. This possibility makes PDA a useful tool for fundamental studies of fouling resistance in surface-modified porous membranes.

The contributions of convective flux, diffusion, surface interactions, and feed solution hydrodynamics to foulant accumulation were discussed by Bacchin et al. [21]. When the forces responsible for foulant removal from the membrane surface are balanced with or exceed the forces responsible for bringing foulants to the membrane surface, no accumulation of foulants occurs [22]. The permeate flux where these forces are balanced is the so-called critical flux (i.e., flux below which no flux-induced fouling occurs) [21, 23-25]. Thus, below the critical flux, the fouling rate is zero [25-27], and the transmembrane pressure (TMP) increases linearly with flux (i.e., the membrane mass transfer resistance is constant and independent of flux) [21, 26-30]. The rate of fouling can be estimated from the rate of TMP change with time (i.e., d(TMP)/dt) [21]. There are two forms of the critical flux: (i) the strong form $\left(\mathrm{J}_{\mathrm{cs}}\right)$, below which the membrane resistance is the same as that during pure water filtration (i.e., the clean membrane resistance), and (ii) the weak form $\left(\mathrm{J}_{\mathrm{cw}}\right)$, below which the membrane resistance is higher than that during pure water filtration as a result of foulant adsorption (but not due to fluxinduced foulant accumulation) $[21,28]$. Another category of critical flux is the critical flux for irreversibility $\left(\mathrm{J}_{\mathrm{ci}}\right)$, which is the flux below which fouling is reversible [21]. 
Membrane operation at zero fouling rate (i.e., below the critical flux) is rarely a realistic possibility $[29,31,32]$. However, a permeate flux below which the rate of fouling is stable and low, but not zero, is often observed. Recently, Field and Pearce defined this flux, which has been referred to as the critical flux in some earlier studies $[25,29,31,33,34]$, as the "threshold flux" [28]. The threshold flux is the flux that separates the low-fouling, stable operating regime from the high-fouling, unstable operating regime [28]. Industrial membrane filtration is often operated near, but below, the highest permeate flux that results in low and acceptable fouling rates so that the operation is most economical [28]. For this reason, the threshold flux may be a more useful benchmark for practical membrane operation than critical flux. Similarities and differences between critical and threshold fluxes have been discussed in several publications $[26,28,30]$. A higher threshold flux allows a membrane to operate at higher capacity (i.e., higher permeate throughput) at a low fouling rate and may prolong the operational time between cleaning steps [28], potentially resulting in long-term capital and operating cost savings. Industrially, membranes are typically operated at constant permeate flux, so laboratory fouling tests at constant flux are more representative of industrial filtrations than tests at constant TMP [26]. Using bench-scale constant flux filtration, the threshold flux can be determined easily and can be used as an indicator of membrane fouling resistance.

This study examines the competing effects of surface hydrophilicity increase and permeance decrease resulting from PDA surface modification of ultrafiltration (UF) membranes via threshold flux measurement. In this work, PDA was chosen as the surface modification agent because it allows independent control of pore size of the modified membranes without substantially affecting hydrophilicity. Polysulfone UF membranes were modified with PDA at different initial dopamine concentrations and deposition 
times. The threshold flux was used to characterize membrane fouling propensity during oil/water emulsion filtration. A simple model foulant of soybean oil emulsion was used, as opposed to other more complex foulant mixtures. In addition, several membrane properties (i.e., surface hydrophilicity, surface roughness, and zeta potential) were investigated. Observed changes in threshold flux due to PDA modification were rationalized by a tradeoff between changes in membrane-foulant hydrophobic interactions and pure water permeance accompanying various modification conditions. The relation between changes in UF pure water permeance and pore size and pore size distribution due to PDA modification are reported separately [9].

\section{BACKGROUND}

\subsection{Threshold Flux Determination}

Methods to measure critical and threshold fluxes are discussed in several publications [21, 29, 32]. A flux stepping method is commonly and conveniently used to determine threshold flux [32]. In the flux stepping method, the permeate flux is increased stepwise, and the TMP at each flux step is recorded $[25,29,31]$. The average TMP $\left(\mathrm{TMP}_{\mathrm{avg}}\right)$ or the rate of fouling $(\mathrm{d}(\mathrm{TMP}) / \mathrm{dt})$ at each flux step is then plotted as a function of flux.

The threshold flux is identified as the flux where the linearity of the $\mathrm{TMP}_{\mathrm{avg}}$ vs. flux curve breaks $[21,25,28]$. Below the threshold flux, the $\mathrm{TMP}_{\mathrm{avg}}$ increases linearly with flux, and total membrane resistance $\left(\mathrm{R}_{\text {total }}=\mathrm{TMP} /\right.$ flux $)$ is constant. Above the threshold flux, the $\mathrm{TMP}_{\mathrm{avg}}$ no longer increases linearly with flux, and $\mathrm{R}_{\text {total }}$ increases as flux increases (i.e., $\mathrm{R}_{\text {total }}$ becomes flux-dependent) $[28,30]$. However, the criterion of linearity of the $\mathrm{TMP}_{\mathrm{avg}}$ vs. flux relationship below the threshold flux has not been standardized among most critical flux and threshold flux studies. In a few studies, values 
of the $\mathrm{R}^{2}$ coefficient of linear regression higher than 0.99 [30] or 0.998 [35] were used to establish the best fit straight line through flux points below the threshold flux. However, in most cases, the linearity of the $\mathrm{TMP}_{\text {avg }}$ vs. flux relationship was established by visual observation, which could result in variations in the estimated threshold flux value.

The threshold flux can also be identified as the flux where d(TMP)/dt increases markedly relative to a regime of low, stable d(TMP)/dt values at lower fluxes $[21,25,28$, $29,31]$. This method directly monitors the increase in fouling rate at the threshold flux. Several studies chose an arbitrary $\mathrm{d}(\mathrm{TMP}) / \mathrm{dt}$ upper limit for the slow-fouling regime, beyond which the rate of fouling and, consequently, d(TMP)/dt increases substantially, to determine the threshold flux $[25,29,31]$. The appropriate $\mathrm{d}(\mathrm{TMP}) / \mathrm{dt}$ limit used for the threshold flux determination usually varies according to membrane type, foulant, and operating conditions such as crossflow velocity. For example, Le Clech et al. used a $\mathrm{d}(\mathrm{TMP}) / \mathrm{dt}$ threshold (i.e., upper limit) of $0.1 \mathrm{mbar} / \mathrm{min}$ to determine threshold fluxes during synthetic and real sewage filtration [29]. In their study, threshold fluxes determined using this $\mathrm{d}(\mathrm{TMP} / \mathrm{dt})$ threshold were almost identical to the threshold fluxes visually identified from the qualitative increase apparent in the d(TMP)/dt vs. flux curves. Beier and Jonsson defined an acceptable fouling rate upper limit of $1.1 \mathrm{~Pa} / \mathrm{s}(40 \mathrm{mbar} / \mathrm{h}$ or $0.67 \mathrm{mbar} / \mathrm{min}$ ) during microfiltration of baker yeast cells, which was used to determine the threshold flux [31]. Choi and Dempsey used statistical analyses (i.e., F-test and t-test) to identify the $\mathrm{d}(\mathrm{TMP}) / \mathrm{dt}$ threshold above which the rate of fouling was non-zero or $\mathrm{d}(\mathrm{TMP}) / \mathrm{dt}$ significantly deviated from values at lower fluxes [25]. They identified the $\mathrm{d}(\mathrm{TMP}) / \mathrm{dt}$ threshold as $0.024 \mathrm{psi} / \mathrm{min}(1.66 \mathrm{mbar} / \mathrm{min})$ for the threshold flux determination during synthetic natural water (i.e., river, spring, or reservoir water) filtration. Although the $\mathrm{d}(\mathrm{TMP}) / \mathrm{dt}$ upper limit is commonly used and provides a convenient approach for threshold flux identification, this criterion is somewhat 
subjective and can vary from one filtration setup (i.e., a particular membrane type, model foulant, or operating condition) to another [25].

The threshold flux may also be determined by plotting the TMP increase during each flux step ( $\triangle \mathrm{TMP})$ against the flux $[18,29,31]$. This $\Delta \mathrm{TMP}$ is calculated from the difference between the final TMP of one flux step and the initial TMP of the following flux step. The threshold flux is identified as the flux where a substantial increase in $\triangle \mathrm{TMP}$ (or its standard deviation) is observed. However, Beier and Jonsson reported large uncertainties in $\triangle \mathrm{TMP}$ values as permeate flux was increased in their study, so an exact threshold flux could not be identified by this method [31]. From flux stepping tests, the $\mathrm{TMP}_{\text {avg }}$ and $\mathrm{d}(\mathrm{TMP}) / \mathrm{dt}$ parameters are more commonly used in the literature and appear to produce more robust threshold flux values than $\triangle \mathrm{TMP}$. For this reason, in our study, we used the $\mathrm{TMP}_{\mathrm{avg}}$ and $\mathrm{d}(\mathrm{TMP}) / \mathrm{dt}$ parameters to estimate threshold fluxes of unmodified and PDA-modified membranes.

\subsection{Factors Influencing Threshold Flux and Local Permeate Flux Concept}

The threshold flux can be influenced by several factors, such as feed solution characteristics, membrane properties, and hydrodynamics at the membrane surface [21, $25,33,34]$. The threshold flux increases with increasing feed particle size $[27,36,37]$, increasing crossflow velocity (i.e., shear stress) [21, 33, 38], and decreasing feed concentration $[27,33,34,39]$. The threshold flux tends to be higher when membrane surface hydrophilicity $[30,36,39]$ or surface charge $[34,39,40]$ leads to weaker or more repulsive membrane-foulant interactions.

A decrease in membrane pore size can lead to higher local permeate flux [41] and a decrease in threshold flux [34]. For some foulant-membrane systems, foulant accumulated during long-term filtration below the threshold flux gradually reduces the 
permeable porous area of the membrane by pore blocking [26, 29, 40-42]. Consequently, local permeate velocity or flux through the remaining open pores increases because overall, global permeate flux is held constant [32,41]. This increase in local flux through the membrane pores results in more severe fouling and a threshold flux decrease [32, 41, 42]. Similarly, surface modification could reduce membrane pore size and increase membrane hydraulic resistance, leading to higher local flux, thereby increasing fouling [18]. There are conflicting reports of the effect of membrane pore size on threshold flux $[27,33,40,43,44]$, and such variations may be due to different foulant sizes relative to membrane pore sizes used in each study.

\section{EXPERIMENTAL}

\subsection{Materials}

Flat-sheet polysulfone ultrafiltration (PS-20 UF) membranes were purchased in rolls from Nanostone Water (Eden Prairie, MN) (formerly Ultura, and Sepro Membranes, Inc. (Oceanside, CA)). Dopamine hydrochloride (3-hydroxytyramine hydrochloride), Trizma hydrochloride (Tris- $\mathrm{HCl}), n$-decane, and potassium chloride $(\mathrm{KCl})$ were purchased from Sigma Aldrich (St. Louis, MO). Sodium hydroxide (NaOH), hydrochloric acid $(\mathrm{HCl})$, and ethanol were purchased from Fisher Scientific (Pittsburgh, PA). Wesson vegetable (100\% soybean) oil was purchased from a local supermarket. Xiameter OFX-0193 (formerly DC193C), which is a silicone-based, non-ionic surfactant, was obtained from Dow Corning (Midland, MI). All chemicals were used as received. Ultrapure water was obtained from a Millipore Milli-Q Advantage A10 water purification system (18.2 M $\Omega$-cm at $25^{\circ} \mathrm{C}, 1.2 \mathrm{ppb}$ TOC) (Billerica, MA). 


\subsection{Polydopamine (PDA) Surface Modification on Membranes}

Polysulfone ultrafiltration (PS-20 UF) membranes (54 kDa MWCO and $\sim 7 \mathrm{~nm}$ nominal pore radius [9]) were pretreated by soaking in ethanol overnight. Each membrane coupon was carefully immersed into the ethanol with the selective surface facing down to avoid air bubbles being trapped inside the pores $[18,20]$. Afterwards, the membrane was rinsed several times in ultrapure water to remove the ethanol. All pretreated membrane samples were stored in ultrapure water until use.

Pretreated membrane samples were modified with PDA by exposing the membrane selective surface to an aqueous dopamine coating solution on a rocking platform shaker (VWR International, Radnor, PA) for the desired coating time. A rocking speed of 30 tilts per minute and a tilt level of 4 were used on this platform shaker during all modification steps. The detailed procedure for membrane modification is provided elsewhere $[9,18,20]$. Dopamine coating solutions were prepared by dissolving dopamine hydrochloride in $15 \mathrm{mM}$ Tris-HCl buffer solution. $100 \mathrm{~mL}$ of dopamine coating solution prepared at the desired initial dopamine concentration was used to coat each membrane sample $\left(345 \mathrm{~cm}^{2}\right.$ coated membrane surface area). The $\mathrm{pH}$ of Tris- $\mathrm{HCl}$ buffer solution was adjusted to 8.8 using $\mathrm{NaOH}$ prior to mixing with dopamine hydrochloride. Several concentrations of dopamine in Tris- $\mathrm{HCl}$ buffer solution and several different coating times were used for the membrane modifications in this study. The initial dopamine solution concentrations were $0.1,0.5,1,2,4$, and $8 \mathrm{mg} / \mathrm{mL}$ at a deposition time of 60 minutes. These initial dopamine solution concentrations could be normalized by the coated membrane surface area of $345 \mathrm{~cm}^{2}$, so initial dopamine concentration per coated membrane area was $3,14,29,58,116$, and $232 \mathrm{mg} / \mathrm{mL} / \mathrm{m}^{2}$, respectively. Generally, the dopamine concentration in the coating solution decreases over time as dopamine reacts to form PDA [45]. Thus, in this study, the dopamine concentration refers to the initial 
dopamine concentration in the modification solution. In addition, membrane samples were coated with PDA at coating times of 15, 30, 60, 120, and 240 minutes, holding the initial dopamine concentration constant at $2 \mathrm{mg} / \mathrm{mL}$. A 60 -minute deposition time and a 2 $\mathrm{mg} / \mathrm{mL}$ initial dopamine concentration were chosen based on the common use of these conditions with membranes in the literature [10, 16, 18, 46, 47]. Following PDA deposition, the modified membrane was rinsed thoroughly with ultrapure water and soaked in ethanol for 10 minutes to remove any weakly-bound PDA. Then, the PDAmodified membrane was rinsed again several times in ultrapure water to ensure complete exchange of ethanol with water. All membranes coated with PDA at various modification conditions were stored in ultrapure water until use.

\subsection{Surface Roughness Measurement}

Membrane surface roughness was characterized using an atomic force microscope (AFM) (Digital Instruments Dimension 3000 with NanoScope software 6.13, Veeco, Plainview, NY) operated in tapping mode. The membranes were vacuum-dried overnight to ensure complete evaporation of liquid from the membrane surfaces and pores. The membrane samples were taped onto Si wafers. The analysis was performed using a $5 \times 5$ $\mu \mathrm{m}$ image size, a $0.5 \mathrm{~Hz}$ scan rate, and a 512 samples/line setting. The root-mean-square roughness $\left(\mathrm{R}_{\mathrm{rms}}\right)$ of each membrane is reported as the average of at least five measurements on membranes at each set of modification conditions considered, and uncertainties represent one standard deviation.

\subsection{Contact Angle Measurement}

Contact angles of membrane surfaces were measured to assess membrane surface hydrophilicity. A contact angle goniometer (Ramé-Hart Model 200) with DROPimage Standard software, version 2.4 (Ramé-Hart Instrument Co., Succasunna, NJ) was used. 
The measurements were performed using a captive bubble method where a static contact angle between a captive $n$-decane bubble in water and the membrane was measured [17, 48]. Membranes were cut into long strips approximately $3-4 \mathrm{~mm}$ wide. Each membrane sample was mounted in a sample holder with its selective surface facing down, and the mounted sample was placed into a transparent chamber filled with ultrapure water. A droplet of $n$-decane was dispensed underneath each membrane sample using a Gilmont Instruments microliter syringe (Cole-Parmer, Vernon Hills, IL) equipped with a J-hook needle. The tip of the needle was placed under the membrane such that the dispensed droplet would rise through the water and contact the feed-side (i.e., selective) face of the membrane. The measured contact angle is the angle between an outer edge of the $n$ decane bubble and the membrane surface as described elsewhere [17]. Each reported contact angle value is an average of at least five measurements on membranes at each set of modification conditions considered, and an average value of the left and right side contact angles was used for each measurement. The uncertainties, denoted by error bars, represent one standard deviation. A smaller contact angle indicates a more hydrophilic membrane surface.

\subsection{Zeta Potential Measurement}

Zeta potentials of unmodified and PDA-modified UF membranes were measured to characterize changes in membrane surface charge due to PDA modification. Membranes coated with PDA at 0.5 and $2 \mathrm{mg} / \mathrm{mL}$ initial dopamine concentrations for 60 minutes were used in this analysis to represent light and moderate PDA coatings, respectively. The zeta potential was determined based on streaming potential measurement using a SurPASS electrokinetic analyzer (Anton Paar, Ashland, VA) with the associated SurPASS software. Each membrane coupon $(25 \times 55 \mathrm{~mm})$ was clamped in 
a flat-sheet tangential flow module equipped with two spacers to create an electrolyte flow channel between the membrane and the reference material. The measurement was performed using $0.001 \mathrm{M} \mathrm{KCl}$ as the background electrolyte solution over a $\mathrm{pH}$ range of $4-10$. The $\mathrm{pH}$ was initially adjusted to 10 by dosing the electrolyte solution with $0.1 \mathrm{M}$ $\mathrm{NaOH}$, and then the $\mathrm{pH}$ was decreased in a stepwise fashion by adding $0.1 \mathrm{M} \mathrm{HCl}$ until the $\mathrm{pH}$ was reduced to 4 . The $\mathrm{pH}$ adjustment was automatically controlled by the instrument. The zeta potential values were evaluated by the SurPASS software using a Fairbrother-Mastin (F-M) model [49, 50]. For each membrane type, the reported zeta potential profile as a function of $\mathrm{pH}$ is representative of at least three replicates. Uncertainties denote one standard deviation. In addition, the zeta potential of the soybean oil emulsion used in this study was measured using a Zetasizer Nano (Malvern Instruments, United Kingdom) at $25^{\circ} \mathrm{C}$ with DTS-1070 cells.

\subsection{Threshold Flux Determination}

Threshold fluxes of unmodified and PDA-modified UF membranes were determined using the flux stepping method at constant permeate flux crossflow filtration $[25,29,31]$. Membranes modified with PDA at initial dopamine concentrations of 0.1 , $0.5,2$, and $8 \mathrm{mg} / \mathrm{mL}$ (using a deposition time of 60 minutes) and deposition times of 15 , 60, and 240 minutes (using an initial dopamine concentration of $2 \mathrm{mg} / \mathrm{mL}$ ) were used in the threshold flux analysis. A 1500 ppm soybean oil emulsion, similar to that used in previous studies $[9,18,20]$, was used as a model foulant feed solution in this study. Xiameter OFX-0193 surfactant was used to stabilize the emulsion. The oil emulsion was prepared by blending $10.8 \mathrm{~g}$ of soybean oil with $1.2 \mathrm{~g}$ of Xiameter OFX-0193 (9:1 ratio of oil to surfactant) in $1 \mathrm{~L}$ of ultrapure water in a high-speed blender (Waring Laboratory, Torrington, CT) at $\sim 20,000 \mathrm{rpm}$ (highest rotational speed) for 3 minutes. The mixture 
was then diluted with $7 \mathrm{~L}$ of ultrapure water, resulting in a $1500 \mathrm{ppm}$ (i.e., $1250 \mathrm{ppm}$ soybean oil and $150 \mathrm{ppm}$ surfactant) soybean oil emulsion (with a total volume of $8 \mathrm{~L}$ ). The oil/water emulsion droplet size and its distribution during the crossflow fouling experiments were measured using an inline liquid particle analyzer (Microflow ${ }^{\mathrm{TM}}$, JM Canty, Inc., Buffalo, NY, USA) and were found to be highly reproducible from batch to batch. These oil droplet size distribution profiles were presented in Figure S.1 in the supplementary information. Mean oil droplet size was approximately $3.0-3.2 \mu \mathrm{m}$, and the standard deviation was approximately $1.6-1.8 \mu \mathrm{m}$, determined from fitting the data to a log-normal distribution.

During constant flux operation, the TMP at each permeate flux was recorded. The permeate flow rate was measured using a Coriolis mass flow meter. The permeate flow rate (and, consequently, permeate flux) was controlled by a peristaltic pump on the permeate line. The peristaltic pump speed was automatically adjusted by a LabVIEW program according to the real-time permeate flow rate measurement from the flow meter. The TMP was measured using a sensitive differential pressure transducer (with an accuracy of $0.08 \%$ of a full scale range of 30 psig or 2.1 barg). More details of the constant flux crossflow filtration system and its operation are provided elsewhere [18, 51]. The flux stepping experiments were conducted with an initial flux of 10 LMH (i.e., $\mathrm{L} / \mathrm{m}^{2} / \mathrm{h}$ ), a step length of 20 minutes, and a step height of $10 \mathrm{LMH}$. The feed flow rate was $0.8 \mathrm{~L} / \mathrm{min}$ (corresponding to a crossflow velocity of $0.18 \mathrm{~m} / \mathrm{s}$ and a Reynolds number of $1000[18,20])$. The feed pressure was 2.1 barg (30 psig). For every filtration test, ultrapure water was initially run at a permeate flux of $10 \mathrm{LMH}$ for at least 20 minutes to ensure that the system had reached steady state. Then, the feed was switched to the 1500 ppm soybean oil emulsion, and the flux stepping experiments were performed by increasing the permeate flux by $10 \mathrm{LMH}$ every 20 minutes. Each flux stepping 
experiment was terminated if the TMP reached the gauge feed pressure, indicating that the permeate line pressure had decreased to atmospheric pressure, as explained in more detail elsewhere $[18,20]$. The temperature of the feed water and feed oil/water emulsion was controlled at $\sim 25^{\circ} \mathrm{C}$ throughout the experiments. The threshold fluxes of unmodified and PDA-modified UF membranes were determined from $\mathrm{TMP}_{\text {avg }}$ vs. flux and $\mathrm{d}(\mathrm{TMP}) / \mathrm{dt}$ vs. flux curves acquired from the flux stepping experiments as explained in the Background and Results and Discussion sections. For each membrane type, the flux stepping profiles determined from repeated filtration tests were nearly identical, suggesting good batch-to-batch reproducibility of the oil/water emulsion and little sample-to-sample variation of the membrane. Each reported $\mathrm{TMP}_{\mathrm{avg}}$ vs. flux profile is representative of at least three replicates. The average $\mathrm{dTMP} / \mathrm{dt}$ in the $\mathrm{dTMP} / \mathrm{dt}$ vs. flux profiles was calculated from $\mathrm{dTMP} / \mathrm{dt}$ results of three membrane samples. The reported threshold flux value determined using the $\mathrm{TMP}_{\mathrm{avg}}$ parameter of each membrane is an average from three membrane samples, and the uncertainties denote one standard deviation.

\section{RESULTS AND DISCUSSION}

\subsection{Membrane Surface Roughness}

The root-mean-square surface roughness $\left(\mathrm{R}_{\mathrm{rms}}\right)$ values of membranes modified with PDA at different initial dopamine concentrations and deposition times are recorded in Table 1 and Table 2, respectively. The surface roughness values of most PDAmodified membranes were statistically identical to that of the unmodified membranes. Thus, there was no obvious change in the membrane surface roughness when initial dopamine concentration or PDA deposition time was varied. The large uncertainties in 
the roughness of some PDA-coated membranes could be due to deposition of PDA aggregates onto the membrane surfaces.

Table 1. Root-mean-square surface roughness $\left(\mathrm{R}_{\mathrm{rms}}\right)$ of unmodified PS-20 UF membranes and membranes modified with PDA at various initial dopamine concentrations (60-minute deposition time).

\begin{tabular}{|c|c|}
\hline $\begin{array}{c}\text { Initial dopamine concentration } \\
(\mathbf{m g} / \mathbf{m L})\end{array}$ & $\mathbf{R}_{\mathbf{r m s}}(\mathbf{n m})$ \\
\hline Unmodified & $4.7 \pm 0.9$ \\
\hline 0.1 & $4.9 \pm 0.3$ \\
\hline 0.5 & $6 \pm 2$ \\
\hline 1 & $6 \pm 2$ \\
\hline 2 & $7 \pm 2$ \\
\hline 4 & $5.0 \pm 0.2$ \\
\hline 8 & $6.2 \pm 0.2$ \\
\hline
\end{tabular}

Table 2. Root-mean-square surface roughness $\left(\mathrm{R}_{\mathrm{rms}}\right)$ of unmodified PS-20 UF membranes and membranes modified with PDA at various deposition times $(2 \mathrm{mg} / \mathrm{mL}$ initial dopamine concentration).

\begin{tabular}{|c|c|}
\hline Deposition time (minutes) & $\mathbf{R}_{\mathbf{r m s}}(\mathbf{n m})$ \\
\hline Unmodified & $4.7 \pm 0.9$ \\
\hline 15 & $5.4 \pm 0.2$ \\
\hline 30 & $5.7 \pm 0.4$ \\
\hline 60 & $7 \pm 2$ \\
\hline 120 & $7.5 \pm 0.6$ \\
\hline 240 & $5.3 \pm 0.5$ \\
\hline
\end{tabular}

In several previous studies, PDA modification increased the roughness of various substrates due to the formation of PDA nanoaggregates on the surfaces [10, 45, 52-57]. Moreover, the roughness increased with increasing dopamine concentration [45] or coating time $[10,45,53,54,57]$, perhaps because the size and number of PDA nanoparticles increased $[10,45,57]$. However, most of the substrates in these previous studies were flat, non-porous surfaces such as glass, $\mathrm{Si}$ wafers, and polymer films. For porous polymer membranes, PDA modification has been reported to either increase or 
decrease surface roughness $[52,58]$. The change in surface roughness could be influenced by a variation in the membrane pore size and porosity [52]. In our study, the native surface of PS-20 UF membranes was not smooth, so PDA coating led to no significant change in membrane surface roughness.

\subsection{Membrane Surface Hydrophilicity}

Figure 1(a) and Figure 1(b) present contact angles of membranes modified with PDA at various initial dopamine concentrations and deposition times, respectively. From Figure 1(a), the contact angle decreased with increasing initial dopamine concentration and plateaued at concentrations greater than $2 \mathrm{mg} / \mathrm{mL}$. The PDA modification significantly increased membrane surface hydrophilicity (i.e., reduced contact angle) regardless of the initial dopamine concentration used, even for initial dopamine concentrations as low as $0.1 \mathrm{mg} / \mathrm{mL}$. The contact angle results of membranes coated at $0.1 \mathrm{mg} / \mathrm{mL}$ and $0.5 \mathrm{mg} / \mathrm{L}$ initial dopamine concentrations had large error bars, suggesting that the PDA coating at these conditions might not be evenly distributed on the membrane surface. Coatings applied at $2 \mathrm{mg} / \mathrm{mL}$ initial dopamine concentrations may have completely covered the surface, so further increases in initial dopamine concentration did not change surface hydrophilicity (i.e., no reduction in contact angle value). 

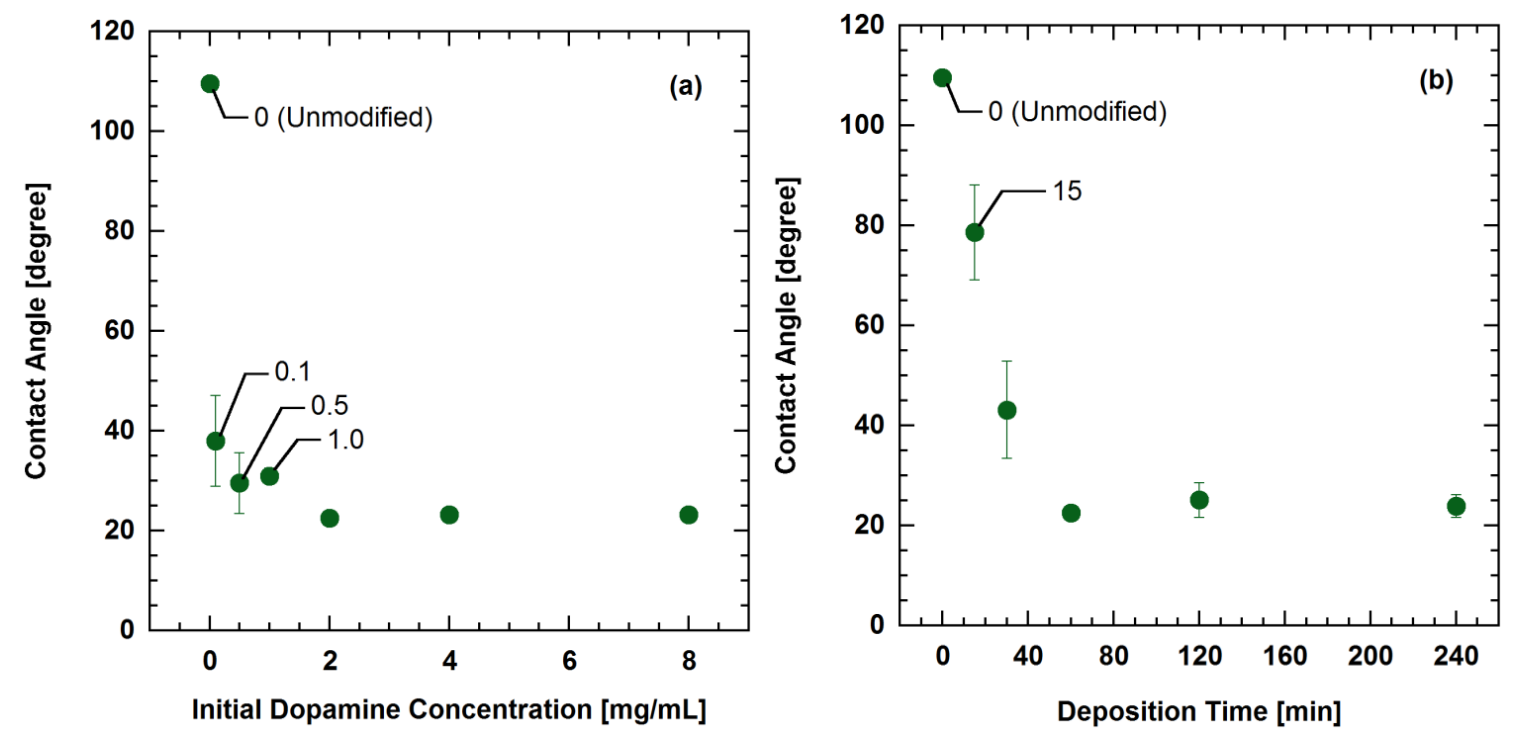

Figure 1. Influence of: (a) initial dopamine concentration and (b) PDA deposition time on contact angle (representing surface hydrophilicity) of unmodified and PDA-modified PS-20 UF membranes. The numbers in (a) and (b) represent initial dopamine concentration in $\mathrm{mg} / \mathrm{mL}$ and deposition time in minutes, respectively. A deposition time of 60 minutes was used in (a), and an initial dopamine concentration of $2 \mathrm{mg} / \mathrm{mL}$ was used in (b).

Figure 1(b) shows that contact angle decreased with increasing PDA deposition time until the coating time reached 60 minutes. For coating times greater than 60 minutes, the contact angle remained constant. Membrane surface hydrophilicity moderately increased at short coating times (i.e., 15 and 30 minutes), suggesting that the membrane surface might only be partially coated with PDA at these conditions. Extending the coating time to 60 minutes increased surface hydrophilicity relative to 15 -minute and 30minute coatings. At longer coating times (i.e., greater than 60 minutes), the membranes may be more completely and homogeneously coated with PDA than those coated at shorter deposition times.

Based on previous studies, the contact angles of various substrates coated with PDA usually converge on the same range regardless of the underlying substrate [12, 59]. 
As proposed in some studies, changes in contact angle induced by PDA deposition could also partly be due to changes in surface roughness [54, 55]. However, in this study, PDA modification did not noticeably change the membrane surface roughness, so the decrease in contact angle was presumed to be primarily influenced by the increase in surface hydrophilicity. The influence of initial dopamine concentration $[10,52,55]$ and PDA deposition time $[10,12,52-55]$ on surface hydrophilicity observed in this study is consistent with earlier literature studies on other substrates.

\subsection{Membrane Zeta Potential}

Figure 2 presents zeta potentials of unmodified and PDA-modified membranes as a function of $\mathrm{pH}$. The zeta potential of the native polysulfone membrane in the $\mathrm{pH}$ range considered was negative, which is consistent with other literature reports [50, 60-62]. Polysulfone does not contain fixed charged groups, so the negative surface charge is ascribed to adsorption of hydroxide ions $\left(\mathrm{OH}^{-}\right)$from aqueous solution onto the membrane surface $[50,60,62]$. This phenomenon is regarded as the cause of apparent negative charge on many neutral hydrophobic surfaces, such as oil droplets and solid hydrophobic polymers [63-66]. 


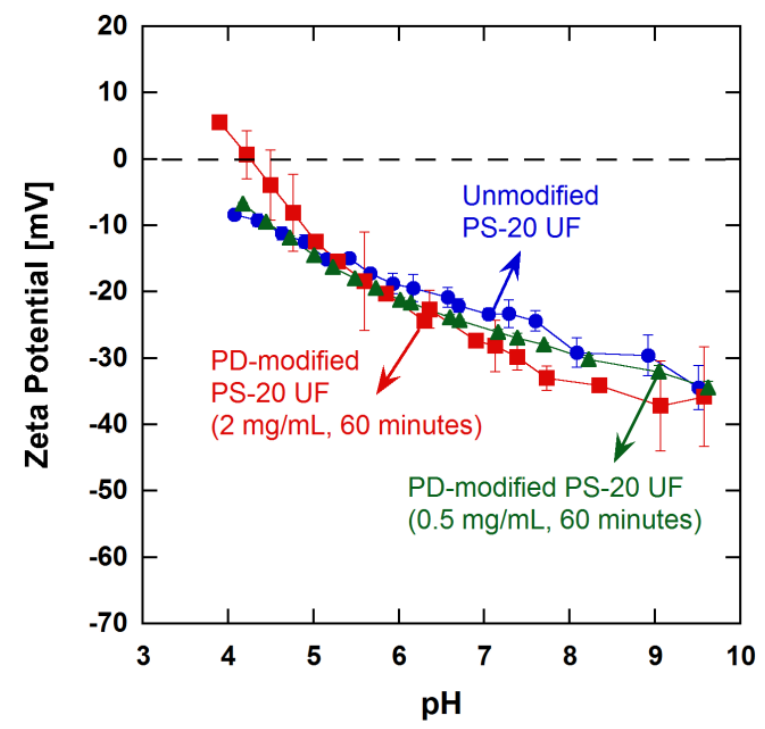

Figure 2. Influence of $\mathrm{pH}$ on zeta potential of unmodified PS-20 UF membranes and membranes modified with PDA at 0.5 and $2 \mathrm{mg} / \mathrm{mL}$ initial dopamine concentrations (60-minute deposition time). Error bars denote one standard deviation.

PDA is believed to be an amphoteric material containing, among other moieties, amine groups and phenolic hydroxyl groups [19, 67-69]. At low $\mathrm{pH}$, amine groups may be protonated from $-\mathrm{NH}$ to $-\mathrm{NH}_{2}^{+}$, and at high $\mathrm{pH}$, phenolic hydroxyl groups can dissociate from $-\mathrm{OH}$ to $-\mathrm{O}^{-}$[19]. At neutral $\mathrm{pH}$, PDA exhibits a negative charge, possibly due to the deprotonation of phenolic hydroxyl groups [67, 70]. Several factors may influence the zeta potential of surface-modified membranes, including the chemical structure of the underlying membranes $[68,71]$, the functional (ionic) groups of the surface-modifying materials [71], and, in the case of polymeric coatings, the coating thickness [72] or grafting density [71, 73].

In our study, the zeta potential of membranes coated with PDA at $0.5 \mathrm{mg} / \mathrm{mL}$ was identical to that of unmodified membranes. This PDA coating condition may result in a coating layer that is too thin (i.e., too little deposited PDA) to influence the membrane 
zeta potential. In another study, a thin poly(ethylene glycol) (PEG) coating had no influence on the zeta potential of the coated substrate, while the zeta potential changed more obviously as PEG coating thickness increased [72]. From Figure 2, the zeta potential profile of membranes coated with PDA at $2 \mathrm{mg} / \mathrm{mL}$ was only slightly different from that of unmodified membranes and qualitatively agrees with those reported in some other studies $[58,74]$. However, in several other publications, the reported zeta potential values of PDA coatings are quite varied [19, 47, 67, 68, 70, 74-77]. The variation in these values could be due to different substrates, PDA deposition conditions, or morphologies of the PDA layer (such as a flat film or a capsule). Different PDA coating concentrations or coating times could result in different PDA coating thicknesses and lead to variations in zeta potential [16]. Zeta potential values of PDA films at neutral $\mathrm{pH}$ from the literature were summarized and compared to results from our study in Table S.1 in the supplementary information.

In this study, the membrane zeta potential was investigated to determine if PDA modification leads to changes in membrane surface charge that might influence fouling and threshold flux. The oil/water emulsion used as a model foulant in this study had a $\mathrm{pH}$ of approximately 5 and a zeta potential of $-13 \pm 0.9 \mathrm{mV}$ at this $\mathrm{pH}$. The negative charge on such emulsions is commonly observed (even if the oil/water emulsion is prepared with a non-ionic surfactant, as was the case here), due to $\mathrm{OH}^{-}$ion adsorption at the oil/water interface [64]. Since oil droplets usually exhibit negative surface charges, membranes may foul less if the membrane surface charge is more negative, due to stronger electrostatic repulsion between the emulsion droplets and the membrane surface $[3,6]$. At $\mathrm{pH} \sim 5$, which was the $\mathrm{pH}$ of the oil/water emulsion used in our fouling experiments, the zeta potential values of unmodified and PDA-modified membranes were approximately the same (cf., Figure 2). Since the zeta potential of the membranes at the conditions used 
for the fouling experiments was not influenced by PDA deposition, changes in membrane surface charge due to PDA modification were presumed to have little effect on fouling in this study.

\subsection{Threshold Fluxes of PDA-Modified Membranes under Oil/Water Emulsion Filtration}

\subsubsection{Criteria for Threshold Flux Determination}

The threshold fluxes of unmodified and PDA-modified PS-20 UF membranes were determined using the flux stepping method described earlier. The TMP and permeate flux profiles of a representative unmodified membrane during a flux stepping experiment are shown in Figure 3(a). Figure 3(b) and Figure 3(c) present $\mathrm{TMP}_{\mathrm{avg}}$ and $\mathrm{d}(\mathrm{TMP}) / \mathrm{dt}$, respectively, as a function of permeate flux from the flux stepping test for the unmodified membrane. 

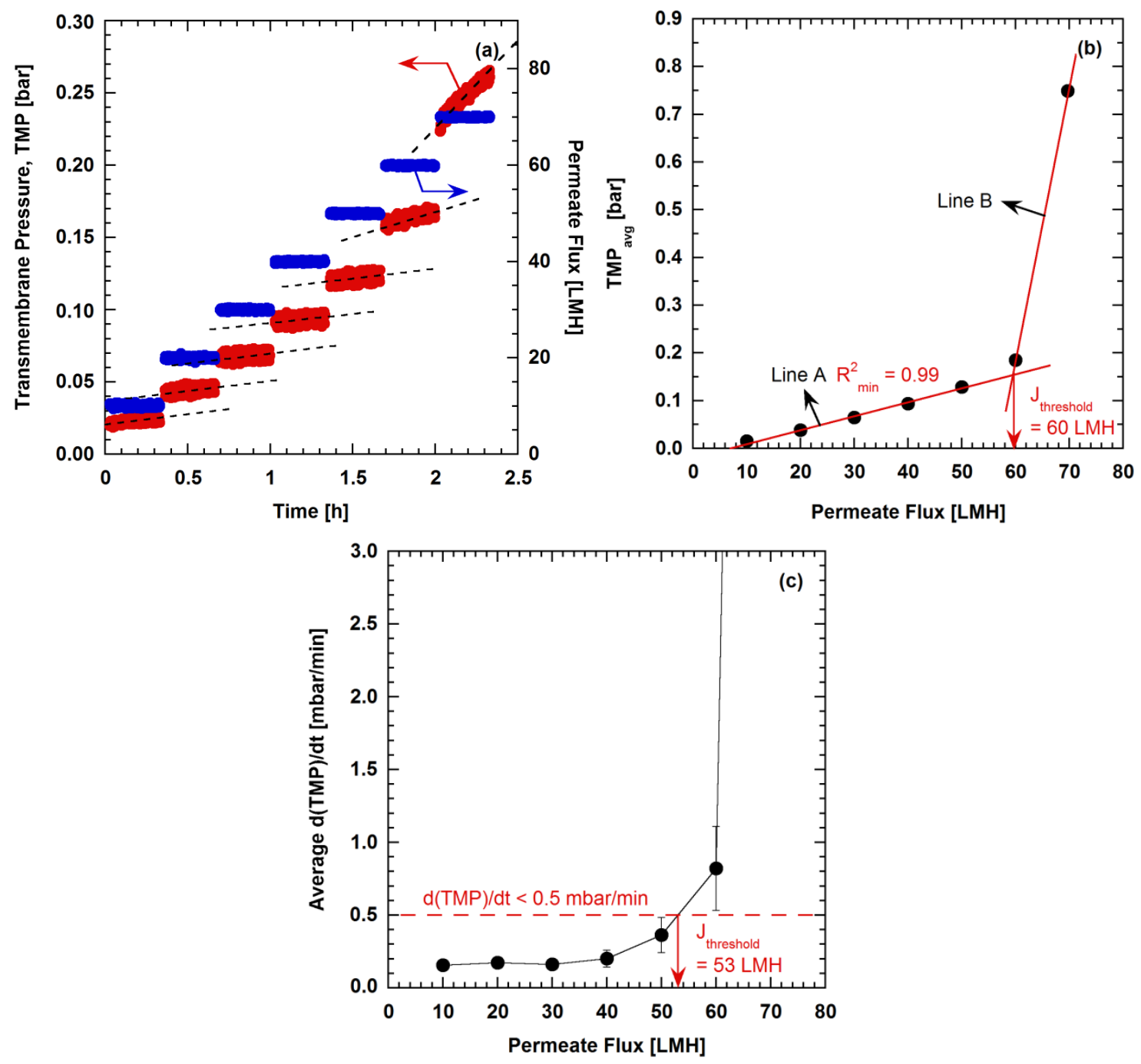

Figure 3. Threshold flux ( $\left.\mathrm{J}_{\text {threshold }}\right)$ determination of unmodified PS-20 UF membranes during oil/water emulsion filtration. (a) TMP and permeate flux profiles during the flux stepping experiment. (b) and (c) represent the threshold flux determination using the $\mathrm{TMP}_{\mathrm{avg}}$ and $\mathrm{d}(\mathrm{TMP}) / \mathrm{dt}$ parameters, respectively. A minimum $\mathrm{R}^{2}$ coefficient $\left(\mathrm{R}^{2}\right.$ min $)$ of 0.99 was used to generate the linear regression line (line A) below the threshold flux in (b). Each plot is representative of at least three replicates. The line in (c) connects average $\mathrm{d}(\mathrm{TMP}) / \mathrm{dt}$ at each flux to guide the eye.

In Figure 3(b), $\mathrm{TMP}_{\mathrm{avg}}$ values were calculated from an average of TMP values recorded during each flux step. From this plot, the first linear regression line (i.e., line A) 
of the data below the threshold flux $\left(\mathrm{J}_{\text {threshold }}\right)$ was established by requiring an $\mathrm{R}^{2}$ coefficient of 0.99 or greater. Above the threshold flux, the membrane fouls rapidly, and TMP usually does not increase linearly with increasing permeate flux [21, 26, 28, 30]. The second linear regression line (i.e., line B) was then drawn from the first two data points beyond the threshold flux. The flux at the intersection of lines A and B was defined as the threshold flux. This flux divides the flux-independent fouling region (i.e., below $\mathrm{J}_{\text {threshold }}$ ) from the flux-dependent fouling region (i.e., above $\mathrm{J}_{\text {threshold }}$ ) [30]. When the minimum $\mathrm{R}^{2}$ value $\left(\mathrm{R}^{2}{ }_{\min }\right)$ of 0.99 was used as shown in Figure $3(\mathrm{~b})$, the threshold flux of the unmodified membrane was $60 \mathrm{LMH}$. This threshold flux value is in the same range as that observed in a previous study with the same membrane and model foulant system [18].

In many studies, a linear relationship of $\mathrm{TMP}_{\mathrm{avg}}$ and permeate flux below the threshold flux was evaluated from visual interpretation of linearity [25, 29, 31, 33, 78$]$. The linearity requirement of the regression line below the threshold flux (i.e., how well the experimental data fit the line) was usually not reported quantitatively. Thus, an exact point where the linearity of the $\mathrm{TMP}_{\mathrm{avg}}$ vs. flux profile breaks (i.e., the threshold flux) could be difficult to determine precisely [78]. The reported threshold flux value may vary according to how the regression at fluxes below the threshold flux (i.e., line A in Figure $3(b))$ is drawn. The influence of the minimum $\mathrm{R}^{2}$ value, which was used to establish line $\mathrm{A}$ in the $\mathrm{TMP}_{\mathrm{avg}}$ vs. flux profile, on the estimated threshold flux was investigated in this study. In addition to Figure $3(\mathrm{~b})$, where an $\mathrm{R}^{2}$ min value of 0.99 was used, threshold flux determinations using the $\mathrm{TMP}_{\text {avg }}$ parameter with $\mathrm{R}_{\text {min }}^{2}$ values of 0.995 and 0.998 are presented in Figure S.2(a) and Figure S.2(b), respectively, in the supplementary information. Three sets of the PDA-modified membrane threshold fluxes determined using $\mathrm{R}_{\text {min }}^{2}$ values of $0.99,0.995$ and 0.998 are compared in Figure S.3(a) and Figure 
$\mathrm{S} .3(\mathrm{~b})$. Higher $\mathrm{R}_{\text {min }}^{2}$ values led to somewhat lower threshold flux values. The $\mathrm{R}_{\text {min }}^{2}$ of 0.99 was chosen in this study because it provided threshold flux values most consistent with long-term filtration results presented earlier [18]. More details about the selection of the $\mathrm{R}_{\text {min }}^{2}$ criterion are provided in the supplementary information. In addition, the regression lines below the threshold flux were established based on a statistical analysis using an F-test to estimate the threshold fluxes of unmodified and PDA-modified membranes. Details of this analysis are discussed in the supplementary information.

In Figure 3(c), d(TMP)/dt values were calculated from the slope of a linear regression (shown with dashed lines in Figure 3(a)) of the TMP vs. time data during each flux step. The reported average d(TMP)/dt values at each flux step in Figure 3(c) is the arithmetic mean of $\mathrm{d}(\mathrm{TMP}) / \mathrm{dt}$ values from three membrane samples at that flux, and the error bars represent one standard deviation. At some permeate fluxes, the error bars are smaller than the symbols in the plot. The standard deviations typically increased in magnitude at fluxes above the threshold flux due to variations in the rate of fouling among different membrane coupons (as observed in other studies [25, 31]). In our study, the $\mathrm{d}(\mathrm{TMP}) / \mathrm{dt}$ limit used for the threshold flux determination was chosen to be 0.5 mbar/min. At this value, the $\mathrm{d}(\mathrm{TMP}) / \mathrm{dt}$ values of most membranes below and above the threshold fluxes were statistically different. Using this approach on the unmodified membrane as an example, Figure 3(c) gives a threshold flux of approximately $53 \mathrm{LMH}$ determined by estimating, using linear interpolation, the flux at which the $\mathrm{d}(\mathrm{TMP}) / \mathrm{dt}$ reached $0.5 \mathrm{mbar} / \mathrm{min}$. This threshold flux value was lower than the value of $65 \mathrm{LMH}$ determined using $\mathrm{d}(\mathrm{TMP}) / \mathrm{dt}$ in our previous study, possibly due to membrane variability from different production batches [18]. Figure 3(c) shows d(TMP)/dt data at different permeate fluxes up to $60 \mathrm{LMH}$ so that the threshold flux determination at a $\mathrm{d}(\mathrm{TMP}) / \mathrm{dt}$ limit of $0.5 \mathrm{mbar} / \mathrm{min}$ limit can be seen more clearly. However, a full profile of the 
$\mathrm{d}(\mathrm{TMP}) / \mathrm{dt}$ vs. flux curve that includes $\mathrm{d}(\mathrm{TMP}) / \mathrm{dt}$ data at all permeate fluxes tested in the flux stepping experiments is shown in Figure S.4.

\subsubsection{Threshold Fluxes of PDA-Modified Membranes}

Figure 4(a) presents estimated threshold fluxes determined using the $\mathrm{TMP}_{\mathrm{avg}}$ parameter for membranes modified with PDA at various initial dopamine concentrations. Figure 4(b) shows similar data for membranes modified with PDA at various deposition times. The $\mathrm{TMP}_{\mathrm{avg}}$ vs. flux plots from the flux stepping experiments and the corresponding threshold flux from each plot are presented in Figures S.5(a) - S.10(a) in the supplementary information. These threshold flux values are also tabulated in Table S.2 and Table S.3 in the supplementary information. In addition, the threshold fluxes determined using the d(TMP)/dt approach are presented in Table S.2 and Table S.3 to compare with threshold fluxes estimated using the $\mathrm{TMP}_{\mathrm{avg}}$ approach. Although the threshold flux values determined using these two approaches were not identical, they were in the same range and had similar trends when PDA modification conditions were changed. The d(TMP)/dt vs. flux plots of PDA-modified membranes are also shown in Figures S.5(b) - S.10(b), and their full profiles are presented in Figures S.5(c) - S.10(c). 

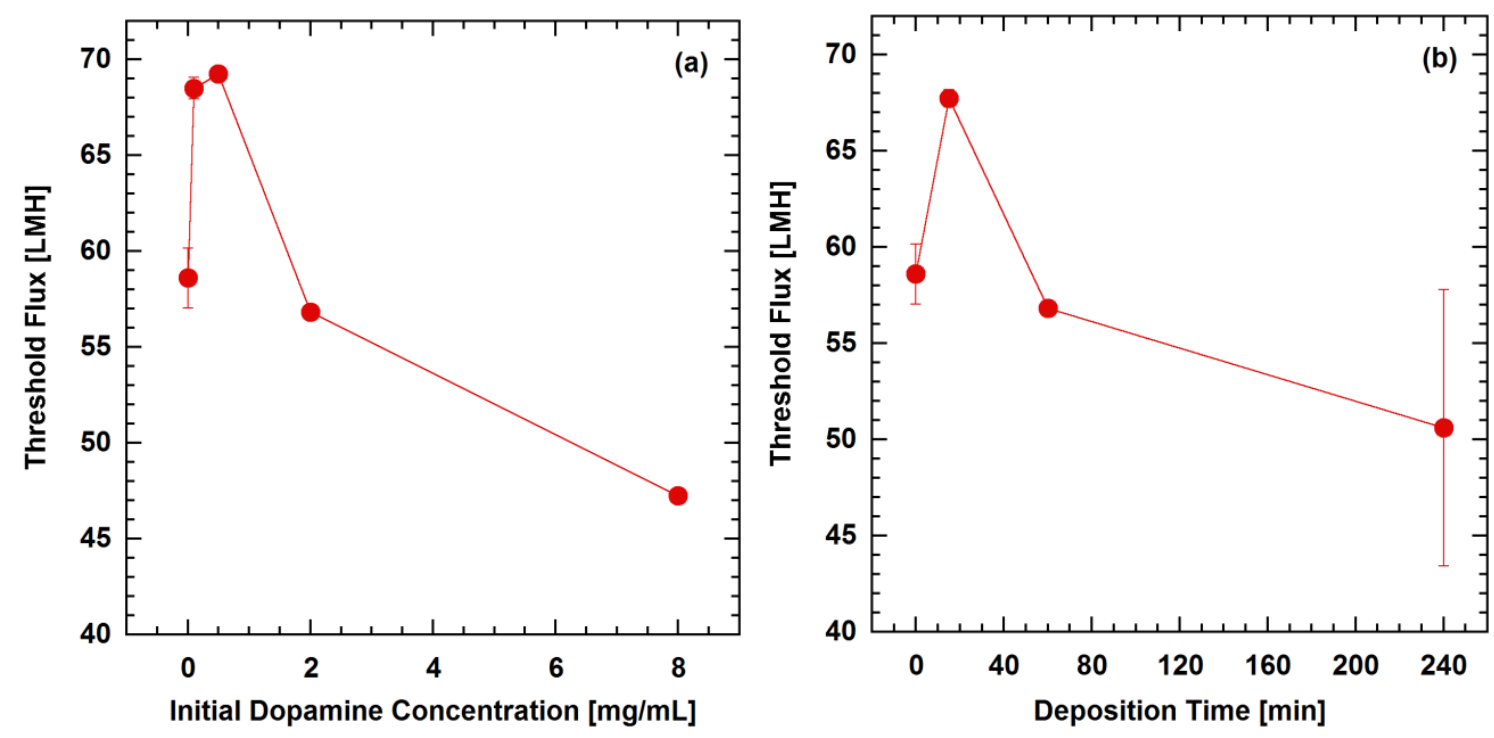

Figure 4. Influence of: (a) initial dopamine concentration and (b) PDA deposition time on the estimated threshold flux of PDA-modified PS-20 UF membranes during oil/water emulsion filtration. The threshold fluxes were determined using the $\mathrm{TMP}_{\mathrm{avg}}$ parameter. A minimum $\mathrm{R}^{2}$ coefficient $\left(\mathrm{R}^{2}{ }_{\text {min }}\right)$ of 0.99 was used to generate the linear regression line below the threshold flux. A deposition time of 60 minutes was used in (a), and an initial dopamine concentration of $2 \mathrm{mg} / \mathrm{mL}$ was used in (b). The threshold flux of the unmodified membranes is shown in (a) as an initial dopamine concentration of zero $\mathrm{mg} / \mathrm{mL}$ and in (b) as a deposition time of zero minutes. At some PDA modification conditions, the error bars are smaller than the symbols in (a) and (b).

The threshold flux increased for membranes prepared using low initial dopamine concentrations or short PDA deposition times. As shown in Figure 4(a), PDA coatings deposited from 0.1 and $0.5 \mathrm{mg} / \mathrm{mL}$ initial dopamine concentrations increased the threshold flux relative to that of unmodified membranes. Similarly, in Figure 4(b), coating the membrane with PDA for 15 minutes enhanced the membrane threshold flux relative to that of unmodified membranes. However, when membranes were coated with PDA using higher initial dopamine concentrations (somewhat greater than $0.5 \mathrm{mg} / \mathrm{mL}$, cf., Figure 4(a)) or longer coating times (somewhat greater than 15 minutes, cf., Figure 
4(b)), the threshold flux decreased. Thus, the threshold flux could be optimized when the membranes were modified with PDA using modification conditions giving low levels of surface modification. The threshold fluxes determined using the $\mathrm{d}(\mathrm{TMP}) / \mathrm{dt}$ approach, shown in Table S.2 and Table S.3, also provided a similar trend as discussed here when the initial dopamine concentration or PDA deposition time was varied.

As discussed earlier, PDA modification significantly increased the membrane surface hydrophilicity even at low initial dopamine concentrations or short deposition times (e.g., 15 minutes). However, PDA modification had a very minor effect on membrane surface roughness and surface charge (as characterized by zeta potential). For this reason, the observed threshold flux increase is attributed mainly to membrane surface hydrophilicity increase due to PDA modification. Enhanced surface hydrophilicity helps reduce hydrophobic interactions, and in turn, adhesion forces between the emulsion droplets and the surface of the native polysulfone membranes [79]. Changes in these hydrophobic interactions are often based on a modification of acid-base (polar) interactions rather than van der Waals or electrostatic interactions $[79,80]$. Thus, the increased surface hydrophilicity makes it more difficult for the emulsion droplets to remain adhered to the membrane surface under a given shear flow [79], thereby reducing fouling and increasing the threshold flux. The threshold flux was reported to be higher for hydrophilic membranes than for hydrophobic membranes in several studies [30, 36, 39].

Despite the increase in surface hydrophilicity, the threshold flux decreased when the membranes were coated more extensively using high initial dopamine concentrations or long coating times. From our previous studies, the pure water permeance values of these highly modified membranes were significantly lower than those of unmodified membranes (cf., Figure 5) [9, 20]. During membrane modification, the PDA not only coats membrane surfaces, but it can also penetrate inside and coat membrane pores [9]. 
The pure water permeance decrease in highly modified membranes is attributed to membrane selective layer thickness increase, pore blockage, and pore size reduction [1, 2]. The PDA coating, as a consequence, decreases the nominal pore size of the membranes [9]. Furthermore, extensive PDA modification narrows the membrane pore size distribution, implying that small pores may be blocked by PDA and large pores may become smaller [9]. Both of these factors reduce pure water permeance (i.e., increase membrane hydraulic resistance to flow). While the global permeate flux over the entire membrane filtration area was maintained, the local permeate flux, which is the flux through individual open pores, was likely increased due to the decreased pore size and decreased number of open pores [41]. The higher local flux could lead to higher permeate drag forces on foulant particles approaching the membranes, leading to more severe fouling [41]. Thus, the higher local flux caused by PDA modification at extreme coating conditions (i.e., high initial dopamine concentration or long deposition time) is a likely cause of the threshold flux decrease observed in this study.

Figure 5 presents the threshold flux and pure water permeance of unmodified and PDA-modified membranes. The observed threshold flux reflects a tradeoff between membrane surface hydrophilicity increase, which tends to increase the threshold flux, and pure water permeance decrease, which tends to decrease the threshold flux, due to PDA modification. The surface hydrophilicity of PDA-modified membranes (average contact angle, $\left.\theta_{\text {avg }}, \approx 30-40^{\circ}\right)$ was higher than that of unmodified membranes $\left(\theta_{\mathrm{UM}} \approx 110^{\circ}\right)$, even for those coated for only 15 minutes. From our earlier studies, membrane pure water permeance decreased with increasing initial dopamine concentration or coating time $[8$, $9,17,20]$. However, the pure water permeance remained near that of unmodified membranes if low initial dopamine concentrations (such as 0.1 and $0.5 \mathrm{mg} / \mathrm{mL}$ ) or short coating times (such as 15 minutes) were used. 


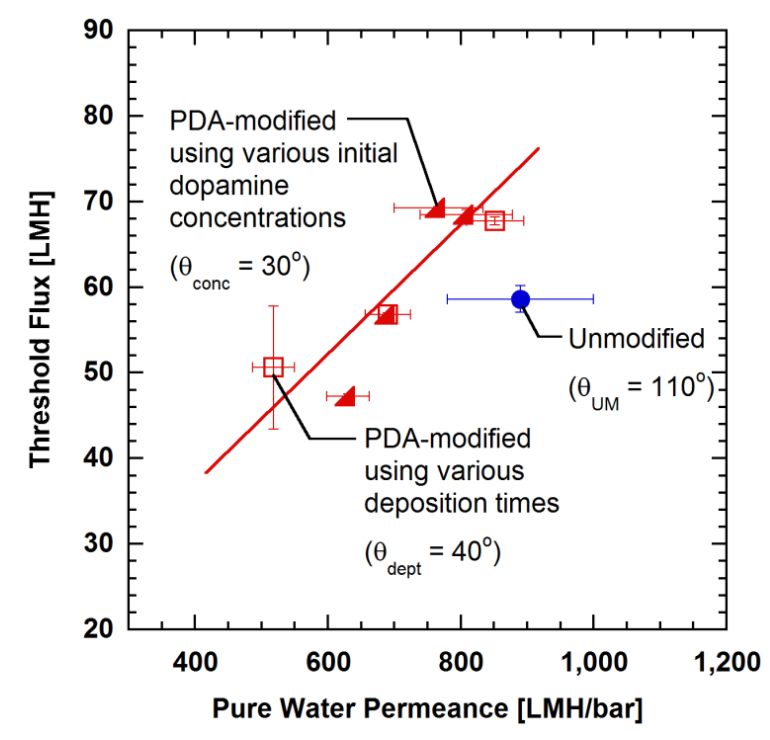

Figure 5. Correlation between pure water permeance and threshold flux of unmodified $(\bullet)$ and PDA-modified PS-20 UF membranes $(\bullet, \square)$. The membranes were modified with PDA at various initial dopamine concentrations (4) of 0.1 , $0.5,2$, and $8 \mathrm{mg} / \mathrm{mL}$ (60-minute deposition time) and at various deposition times $(\square)$ of 15,60 , and 240 minutes $(2 \mathrm{mg} / \mathrm{mL}$ initial dopamine concentration). $\theta_{\mathrm{UM}}$ represents the contact angle of unmodified membranes. $\theta_{\text {conc }}$ and $\theta_{\text {dept }}$ are average contact angles of membranes modified with PDA at various initial dopamine concentrations and various deposition times, respectively. The line is to guide the eye for the data trend of PDA-modified membranes. Pure water permeance values were taken from [9].

Figure 5 summarizes the effects of pure water permeance and hydrophilicity on threshold flux. For unmodified and PDA-modified membranes with pure water permeance values in a similar range, the PDA-modified membranes had higher threshold fluxes than unmodified membranes, presumably because of higher surface hydrophilicity. However, when pure water permeance of the PDA-modified membranes decreased relative to that of unmodified membranes due to more extensive surface modification, the threshold flux of PDA-modified membranes was lower than that of unmodified membranes despite the higher surface hydrophilicity of the modified membranes. In addition, among the membranes coated with PDA at various modification conditions, the 
threshold flux decreased with decreasing pure water permeance. Membranes with low pure water permeance likely have smaller pore sizes and, therefore, higher local flux than membranes with high pure water permeance, leading to lower threshold flux values.

\section{CONCLUSIONS}

Polysulfone ultrafiltration membranes were modified with polydopamine (PDA) using various initial dopamine concentrations and deposition times. In this study, membrane properties related to fouling (i.e., surface hydrophilicity, roughness, and charge) were investigated. PDA modification increased membrane surface hydrophilicity regardless of the modification conditions used. The membrane surface roughness and surface charge, characterized by zeta potential, did not noticeably change following PDA modification. The threshold flux increased when PDA modification was applied at relatively low initial dopamine concentration (e.g., $0.5 \mathrm{mg} / \mathrm{mL}$ and a coating time of 60 minutes) or short deposition time (e.g., 15 minutes and a coating concentration of 2 $\mathrm{mg} / \mathrm{mL}$ ). Changes in threshold flux were governed by a tradeoff between membrane surface hydrophilicity increase and pure water permeance decrease due to PDA modification. When low initial dopamine concentrations or short coating times were used, the threshold flux of PDA-modified membranes increased. In contrast, the threshold flux decreased when membranes were modified with PDA at high initial dopamine concentrations or long coating times. With excessive PDA deposition, the membrane pure water permeance decreased significantly, and some membrane pores may have been blocked and the pore size may have been reduced. Thus, the local permeate flux was likely increased in highly modified membranes, leading to more severe fouling and a threshold flux decrease even though the surface hydrophilicity was improved. 


\section{ACKNOWLEDGEMENTS}

The authors gratefully acknowledge financial support from the National Science Foundation Science and Technology Center for Layered Polymeric Systems (DMR0423914) and National Science Foundation grants CBET-1160069 and CBET 1403670. This work was also partially supported by the International Institute for Carbon-Neutral Energy Research (WPI-I2CNER), Kyushu University of World Premier International Research Center Initiative (WPI), MEXT, Japan.

\section{REFERENCES}

[1] R.W. Baker, Membrane Technology and Applications, 2nd ed., John Wiley \& Sons Ltd., West Sussex, England, 2004.

[2] L.J. Zeman, A.L. Zydney, Microfiltration and Ultrafiltration: Principles and Applications, Marcel Dekker, Inc., New York, NY, 1996.

[3] J.S. Louie, I. Pinnau, I. Ciobanu, K.P. Ishida, A. Ng, M. Reinhard, Effects of polyether-polyamide block copolymer coating on performance and fouling of reverse osmosis membranes, Journal of Membrane Science 280 (2006) 762-770.

[4] D. Rana, T. Matsuura, Surface modifications for antifouling membranes, Chemical Reviews 110 (2010) 2448-2471.

[5] K. Kato, E. Uchida, E.-T. Kang, Y. Uyama, Y. Ikada, Polymer surface with graft chains, Progress in Polymer Science 28 (2003) 209-259.

[6] P. Le-Clech, V. Chen, A.G. Fane, Fouling in membrane bioreactors used in wastewater treatment, Journal of Membrane Science 284 (2006) 17-53.

[7] J. Gilron, S. Belfer, P. Vaisanen, M. Nystrom, Effects of surface modification on antifouling and performance properties of reverse osmosis membranes, Desalination 140 (2001) 167-179.

[8] B.D. McCloskey, H.B. Park, H. Ju, B.W. Rowe, D.J. Miller, B.J. Chun, K. Kin, B.D. Freeman, Influence of polydopamine deposition conditions on pure water flux and foulant adhesion resistance of reverse osmosis, ultrafiltration, and microfiltration membranes, Polymer 51 (2010) 3472-3485.

[9] S. Kasemset, L. Wang, Z. He, D.J. Miller, A. Kirschner, B.D. Freeman, M.M. Sharma, Influence of polydopamine deposition conditions on hydraulic permeability, sieving coefficients, pore size and pore size distribution for a polysulfone ultrafiltration membrane, Journal of Membrane Science (2015) submitted.

[10] C. Cheng, S. Li, W. Zhao, Q. Wei, S. Nie, S. Sun, C. Zhao, The hydrodynamic permeability and surface property of polyethersulfone ultrafiltration membranes with mussel-inspired polydopamine coatings, Journal of Membrane Science 417-418 (2012) $228-236$. 
[11] H. Lee, S.M. Dellatore, W.M. Miller, P.B. Messersmith, Mussel-inspired surface chemistry for multifunctional coatings, Science 318 (2007) 426-430.

[12] K. Kang, I.S. Choi, Y. Nam, A biofunctionalization scheme for neural interfaces using polydopamine polymer, Biomaterials 32 (2011) 6374-6380.

[13] H. Wei, J. Ren, B. Han, L. Xu, L. Han, L. Jia, Stability of polydopamine and poly(DOPA) melanin-like films on the surface of polymer membranes under strongly acidic and alkaline conditions, Colloids and Surfaces B: Biointerfaces 110 (2013) 22-28. [14] D. Schaubroeck, Y. Vercammen, L.V. Vaeck, E. Vanderleyden, P. Dubruel, J. Vanfleteren, Surface characterization and stability of an epoxy resin surface modified with polyamines grafted on polydopamine, Applied Surface Science 303 (2014) 465-472. [15] D.J. Miller, X. Huang, H. Li, S. Kasemset, A. Lee, D. Agnihotri, T. Hayes, D.R. Paul, B.D. Freeman, Fouling-resistant membranes for the treatment of flowback water from hydraulic shale fracturing: A pilot study, Journal of Membrane Science 437 (2013) 265-275.

[16] B.D. McCloskey, H.B. Park, H. Ju, B.W. Rowe, D.J. Miller, B.D. Freeman, A bioinspired fouling-resistant surface modification for water purification membranes, Journal of Membrane Science 413-414 (2012) 82-90.

[17] S. Kasemset, A. Lee, D.J. Miller, B.D. Freeman, M.M. Sharma, Effect of polydopamine deposition conditions on fouling resistance, physical properties, and permeation properties of reverse osmosis membranes in oil/water separation, Journal of Membrane Science 425-426 (2013) 208-216.

[18] D.J. Miller, S. Kasemset, L. Wang, D.R. Paul, B.D. Freeman, Constant flux crossflow filtration evaluation of surface-modified fouling-resistant membranes, Journal of Membrane Science 452 (2014) 171-183.

[19] M. Vaselbehagh, H. Karkhanechi, S. Mulyati, R. Takagi, H. Matsuyama, Improved antifouling of anion-exchange membrane by polydopamine coating in electrodialysis process, Desalination 332 (2014) 126-133.

[20] D.J. Miller, D.R. Paul, B.D. Freeman, An improved method for surface modification of porous water purification membranes, Polymer 55 (2014) 1375-1383.

[21] P. Bacchin, P. Aimar, R.W. Field, Critical and sustainable fluxes: Theory, experiments and applications, Journal of Membrane Science 281 (2006) 42-69.

[22] D. Jiao, M.M. Sharma, Mechanism of cake buildup in crossflow filtration of colloidal suspensions, Journal of Colloid and Interface Science 162 (1994) 454-462. [23] R.W. Field, D. Wu, J.A. Howell, B.B. Gupta, Critical flux concept for microfiltration fouling, Journal of Membrane Science 100 (1995) 259-272. [24] J.A. Howell, Sub-critical flux operation of microfiltration, Journal of Membrane Science 107 (1995) 165-171.

[25] K.Y. Choi, B.A. Dempsey, Bench-scale evaluation of critical flux and TMP in lowpressure membrane filtration, Journal of American Water Works Association 97 (2005) 134-143.

[26] D.J. Miller, S. Kasemset, D.R. Paul, B.D. Freeman, Comparison of membrane fouling at constant flux and constant transmembrane pressure conditions, Journal of Membrane Science 454 (2014) 505-515. 
[27] D.Y. Kwon, S. Vigneswaran, A.G. Fane, R.B. Aim, Experimental determination of critical flux in cross-flow microfiltration, Separation and Purification Technology 19 (2000) 169-181.

[28] R.W. Field, G.K. Pearce, Critical, sustainable and threshold fluxes for membrane filtration with water industry applications, Advances in Colloid and Interface Science 164 (2011) 38-44.

[29] P. Le-Clech, B. Jefferson, I.S. Chang, S.J. Judd, Critical flux determination by the flux-step method in a submerged membrane bioreactor, Journal of Membrane Science 227 (2003) 81-93.

[30] J. Luo, S.T. Morthensen, A.S. Meyer, M. Pinelo, Filtration behavior of casein glycomacropeptide (CGMP) in an enzymatic membrane reactor: fouling control by membrane selection and threshold flux operation, Journal of membrane Science 469 (2014) 127-139.

[31] S.P. Beier, G. Jonsson, Critical flux determination by flux-stepping, AIChE Journal 56 (2010) 1739-1747.

[32] B.D. Cho, A.G. Fane, Fouling transients in nominally sub-critical flux operation of a membrane bioreactor, Journal of Membrane Science 209 (2002) 391-403.

[33] S.S. Madaeni, A.G. Fane, D.E. Wiley, Factors influencing critical flux in membrane filtration of activated sludge, Journal of Chemical Technology and Biotechnology 74 (1999) 539-543.

[34] V. Chen, Performance of partially permeable microfiltration membranes under low fouling conditions, Journal of Membrane Science 147 (1998) 265-278.

[35] J. Luo, L. Ding, Y. Wan, M.Y. Jaffrin, Threshold flux for shear-enhanced nanofiltration: Experimental observation in dairy wastewater treatment, Journal of Membrane Science 409-410 (2012) 276-284.

[36] L. Defrance, M.Y. Jaffrin, Comparison between filtrations at fixed transmembrane pressure and fixed permeate flux: application to a membrane bioreactor used for wastewater treatment, Journal of Membrane Science 152 (1999) 203-210.

[37] H. Li, A.G. Fane, H.G.L. Coster, S. Vigneswaran, An assessment of depolarisation models of crossflow microfiltration by direct observation through the membrane, Journal of Membrane Science 172 (2000) 135-147.

[38] V. Chen, A.G. Fane, S. Madaeni, I.G. Wenten, Particle deposition during membrane filtration of colloids: transition between concentration polarization and cake formation, Journal of Membrane Science 125 (1997) 109-122.

[39] S. Metsämuuronen, J. Howell, M. Nyström, Critical flux in ultrafiltration of myoglobin and baker's yeast, Journal of Membrane Science 196 (2002) 13-25.

[40] M. Mänttäri, M. Nyström, Critical flux in NF of high molar mass polysaccharides and effluents from the paper industry, Journal of Membrane Science 170 (2000) 257-273. [41] S. Ognier, C. Wisniewski, A. Grasmick, Membrane bioreactor fouling in sub-critical filtration conditions: A local critical flux concept, Journal of Membrane Science 229 (2004) 171-177. 
[42] J. Zhang, H.C. Chua, J. Zhou, A.G. Fane, Factors affecting the membrane performance in submerged membrane bioreactors, Journal of Membrane Science 284 (2006) 54-66.

[43] D. Wu, J.A. Howell, R.W. Field, Critical flux measurement for model colloids, Journal of Membrane Science 152 (1999) 89-98.

[44] Z. Wu, Z. Wang, S. Huang, S. Mai, C. Yang, X. Wang, Z. Zhou, Effects of various factors on critical flux in submerged membrane bioreactors for municipal wastewater treatment, Separation and Purification Technology 62 (2008) 56-63.

[45] V. Ball, D.D. Frari, V. Toniazzo, D. Ruch, Kinetics of polydopamine film deposition as a function of $\mathrm{pH}$ and dopamine concentration: Insights in the polydopamine deposition mechanism, Journal of Colloid and Interface Science 386 (2012) 366-372.

[46] J.T. Arena, B.D. McCloskey, B.D. Freeman, J.R. McCutcheon, Surface modification of thin film composite membrane support layers with polydopamine: Enabling use of reverse osmosis membranes in pressure retarded osmosis, Journal of Membrane Science 375 (2011) 55-62.

[47] R. Zhang, Y. Su, X. Zhao, Y. Li, J. Zhao, Z. Jiang, A novel positively charged composite nanofiltration membrane prepared by bio-inspired adhesion of polydopamine and surface grafting of poly(ethylene imine), Journal of Membrane Science 470 (2014) 9-17.

[48] E.M. Van Wagner, A.C. Sagle, M.M. Sharma, Y.-H. La, B.D. Freeman, Surface modification of commercial polyamide desalination membranes using poly(ethylene glycol) diglycidyl ether to enhance membrane fouling resistance, Journal of Membrane Science 367 (2011) 273-287.

[49] C. Werner, H. Körber, R. Zimmermann, S. Dukhin, H.-J. Jacobasch, Extended electrokinetic characterization of flat solid surfaces, Journal of Colloid and Interface Science 208 (1998) 329-346.

[50] D. Möckel, E. Staude, M. Dal-Cin, K. Darcovich, M. Guiver, Tangential flow streaming potential measurements: Hydrodynamic cell characterization and zeta potentials of carboxylated polysulfone membranes, Journal of Membrane Science 145 (1998) 211-222.

[51] D.J. Miller, D.R. Paul, B.D. Freeman, A crossflow filtration system for constant permeate flux membrane fouling characterization, Review of Scientific Instruments 84 (2013) 035003.

[52] Z. Xi, Y. Xu, L. Zhu, Y. Wang, B. Zhu, A facile method of surface modification for hydrophobic polymer membranes based on the adhesive behavior of poly(DOPA) and poly(dopamine), Journal of Membrane Science 327 (2009) 244-253.

[53] Y.M. Shin, Y.B. Lee, H. Shin, Time-dependent mussel-inspired functionalization of poly(L-lactide-co-e-caprolactone) substrates for tunable cell behaviors, Colloids and Surfaces B: Biointerfaces 87 (2011) 79-87.

[54] J. Ou, J. Wang, S. Liu, J. Zhou, S. Ren, S. Yang, Microtribological and electrochemical corrosion behaviors of polydopamine coating on APTS-SAM modified Si substrate, Applied Surface Science 256 (2009) 894-899. 
[55] J. Jiang, L. Zhu, L. Zhu, B. Zhu, Y. Xu, Surface characteristics of a self-polymerized dopamine coating deposited on hydrophobic polymer films, Langmuir 27 (2011) 1418014187.

[56] Q. Wei, F. Zhang, J. Li, B. Li, C. Zhao, Oxidant-induced dopamine polymerization for multifunctional coatings, Polymer Chemistry 1 (2010) 1430-1433.

[57] R.A. Zangmeister, T.A. Morris, M.J. Tarlov, Characterization of polydopamine thin films deposited at short times by autoxidation of dopamine, Langmuir 29 (2013) 86198628.

[58] B.D. McCloskey, Novel surface modifications and materials for fouling resistant water purification membranes, $\mathrm{PhD}$ thesis, University of Texas at Austin, 2009. [59] Y. Liu, K. Ai, L. Lu, Polydopamine and its derivative materials: Synthesis and promising applications in energy, environmental, and biomedical fields, Chemical Reviews 114 (2014) 5057-5115.

[60] R. Blank, K.-H. Muth, S. Proske-Gerhards, E. Staude, Electrokinetic investigations of charged porous membranes, Colloids and Surfaces A: Physicochemical and Engineering Aspects 140 (1998) 3-11.

[61] X. Huang, D. Guduru, Z. Xu, J. Vienken, T. Groth, Blood compatibility and permeability of heparin-modified polysulfone as potential membrane for simultaneous hemodialysis and LDL removal, Macromolecular Bioscience 11 (2011) 131-140. [62] K.J. Kim, A.G. Fane, M. Nystrom, A. Pihlajamaki, W.R. Bowen, H. Mukhtar, Evaluation of electroosmosis and streaming potential for measurement of electric charges of polymeric membranes, Journal of Membrane Science 116 (1996) 149-159.

[63] J.K. Beattie, The intrinsic charge on hydrophobic microfluidic substrates, Lab on a Chip 6 (2006) 1409-1411.

[64] K.G. Marinova, R.G. Alargova, N.D. Denkov, O.D. Velev, D.N. Petsev, I.B. Ivanov, R.P. Borwankar, Charging of oil-water interfaces due to spontaneous adsorption of hydroxyl ions, Langmuir 12 (1996) 2045-2051.

[65] R. Zangi, J.B.F.N. Engberts, Physisorption of hydroxide ions from aqueous solution to a hydrophobic surface, Journal of the American Chemical Society 127 (2005) 22722276.

[66] K.N. Kudin, R. Car, Why are water-hydrophobic interfaces charged?, Journal of the American Chemical Society 130 (2008) 3915-3919.

[67] B. Yu, J. Liu, S. Liu, F. Zhou, Pdop layer exhibiting zwitterionicity: a simple electrochemical interface for governing ion permeability, Chemical Communications 46 (2010) 5900-5902.

[68] H. Karkhanechi, R. Takagi, H. Matsuyama, Biofouling resistance of reverse osmosis membrane modified with polydopamine, Desalination 336 (2014) 87-96.

[69] D.R. Dreyer, D.J. Miller, B.D. Freeman, D.R. Paul, C.W. Bielawski, Elucidating the structure of poly(dopamine), Langmuir 28 (2012) 6428-6435.

[70] K.Y. Kim, E. Yang, M.Y. Lee, K.J. Chae, C.M. Kim, I.S. Kim, Polydopamine coating effects on ultrafiltration membrane to enhance power density and mitigate biofouling of ultrafiltration microbial fuel cells (UF-MFCs), Water Research 54 (2014) $62-68$. 
[71] H. Susanto, M. Balakrishnan, M. Ulbricht, Via surface functionalization by photograft copolymerization to low-fouling polyethersulfone-based ultrafiltration membranes, Journal of Membrane Science 288 (2007) 157-167.

[72] Y.M. Chan, R. Schweiss, C. Werner, M. Grunze, Electrokinetic characterization of oligo- and poly(ethylene glycol)-terminated self-assembled monolayers on gold and glass surfaces, Langmuir 19 (2003) 7380-7385.

[73] H. Susanto, M. Ulbricht, Photografted thin polymer hydrogel layers on PES ultrafiltration membranes: Characterization, stability, and influence on separation performance, Langmuir 23 (2007) 7818-7830.

[74] V. Ball, Impedance spectroscopy and zeta potential titration of dopa-melanin films produced by oxidation of dopamine, Colloids and Surfaces A: Physicochemical and Engineering Aspects 363 (2010) 92-97.

[75] S. Azari, L. Zou, Using zwitterionic amino acid L-DOPA to modify the surface of thin film composite polyamide reverse osmosis membranes to increase their fouling resistance, Journal of Membrane Science 401-402 (2012) 68-75.

[76] Y. Zhang, B.M. Teo, K.N. Goldie, B. Städler,

Poly(N-isopropylacrylamide)/poly(dopamine) capsules, Langmuir 30 (2014) 5592-5598.

[77] Q. Liu, B. Yu, W. Ye, F. Zhou, Highly selective uptake and release of charged molecules by $\mathrm{pH}$-responsive polydopamine microcapsules, Macromolecular Bioscience 11 (2011) 1227-1234.

[78] I.H. Huisman, E. Vellenga, G. Trägårdh, C. Trägårdh, The influence of the membrane zeta potential on the critical flux for crossflow microfiltration of particle suspensions, Journal of Membrane Science 156 (1999) 153-158.

[79] A.M. Freitas, M.M. Sharma, Effect of surface hydrophobicity on the hydrodynamic detachment of particles from surfaces, Langmuir 15 (1999) 2466-2476.

[80] C.J. Van Oss, M.K. Chaudhury, R.J. Good, Interfacial Lifshitz-van der Waals and polar interactions in macroscopic systems, Chemical Reviews 88 (1988) 927-941. 


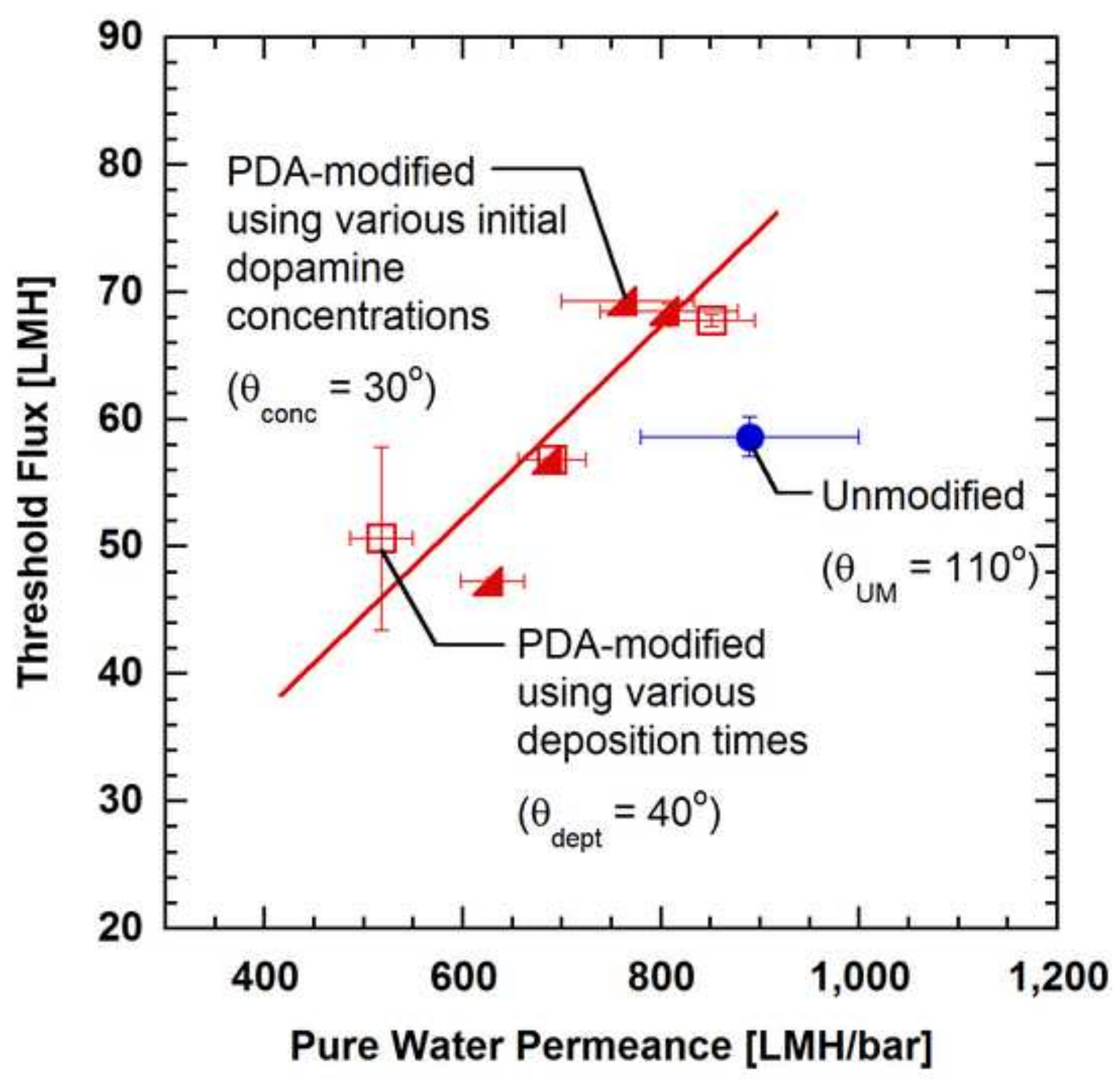

